\title{
Harmonized School Management: A Product of Law-based Communication Behavior (Management Experience in BDK High School, Berat, Albania)
}

\begin{abstract}
Yzedin Hajdaraj
Albanian University, Berat, Albania

Communication behavior is one of the key indicators of humanity in civilized societies in today's era. In order to be contemporary, it should be law-based. Being a law-based communication behavior, it is respected from all the personnel who have a direct relationship of interest to the executives who are responsible for the management of the educational institution. A wise, gentle, and law-based communication is persuasive for everyone, even for those who do not feel comfortable with the principal in the very first moments of his/her duty. A law-based behavior consists of equality and justice. These indicators make individuals feel good with their work relationships and social duty either vertical or horizontal. Harmonization means workload, facilities, appreciation, and respect for everyone. Balancing all these elements demands attention and careness from the head of the educational institution which accomplishes a harmonized management and success in educational service as a mission of the school to the community. The aim of this paper is to feature the law-based requirement of school management, free from violence and arrogance of heads. The management in-group is the best way of managing in modern times. We need to answer some questions which form the core of the paper: What is the meaning of the harmonized management? How does it start? What are its elements? How is the law-based behavior of the principal reflected to the personnel/staff? What is its effect and product? The hypothesis is the law-based behavior of the principal harmonizes school management. The study was conducted in BabëDudë (Karbunara) High School in Berat, Albania. These are the methods used in this research paper: observation, experiment, case study, and comparison.
\end{abstract}

Keywords: management, school, harmonization, communication, law-based behavior

\section{Introduction}

At first glance of the phrase "harmonized school management" appeared to be abstract. Maybe someone cannot even understand it. Harmonized management? How? How come? Only those who can accomplish this management can think and consider it. The others cannot even imagine it. The concept harmonized management means that all elements, actors, and factors that have a connection, interdependence, and relationship with the institution to be fully coherent, coordinated, and cooperating with each other to achieve the objectives. Harmonization of these components depends on if these elements exist in the vision of the head of the educational institution and furthermore, if he/she has the will and passion to fulfill them. What is more

Yzedin Hajdaraj, Ph.D. candidate, part-time lecturer, Educational Department, Albanian University. 
important is that his/her will, ability, persistence, and dedication turn out to be his/her goal of his/her moral, ethical, and professional ego, creating a social relief to others and himself/herself. The presence of another better man will lead poor individuals toward good behavior. The head of the institution needs to show that he/she knows and loves. When the staff/personnel understand that he/she has both these values, they patiently wait and welcome their implementation. Those from the staff/personnel who do not like these values, they are initially distrustful expressing irony, laughter, and sub-texts, then they put stones under the wheels with secret methods, later they silence. Eventually, they can and act like others, doing the right thing.

Harmonized management firstly requires that the head of the institution needs to be harmonized with his/her family and friends. If the staff does not recognize as such, you do not have the moral right to put others on track. In this case the head is not a model to follow. He/she does not know that well himself/herself and it is apparent that he/she is on the wrong track. This is the delicate moment when people make bad decisions. Knowing others is a skill, but knowing yourself is true wisdom. Harmonization of personnel is easily performed when they see that there is a harmonized head in charge. A principal who thinks that he/she is not going to command or give orders, but he/she is going to be a model for the staff working in that institution will make it easier to harmonize even the most divided staff or personnel. Equality and justice criteria used with love and respect without bias are a faster step towards harmonization. Another reason to be more motivated is by delegating each responsibility or competence to the competent individuals of each institution. We need to feel competent in our environment. In those institutions where each of the individuals feels his/her heroes in the legal limits and feels appreciated for what he/she does, there comes the psychological basis of harmonization as an indicator of management philosophy.

\section{Aim and Objectives}

The essence of the purpose of this paper is concerned with that which happens in an institution where individuals communicate through a law-based behavior and the staff and personnel understand. In this case, the success of management is guaranteed. Society accepts everything that is law-based and follows it with full conviction and wisdom. The experience at BabëDudë (Karbunara) High School in Berat clearly proves it. Heads of institutions who do not intend to benefit from their position and their pragmatic philosophy does not include such thing; achieve great success in quite a while.

Philosophical theories of management are clear. They have no need for interpretation, but they only need to be strictly applied. Whenever an individual establishes his own job taking care and responsibility of it, it becomes easy for him/her to argue and defend, perhaps even recommend the best way possible. Objectives are alleviated when work is implemented by the researcher. Here, some of which may be included in this paper:

1. To define the concept of harmonized management;

2. To analyze the elements of this management;

3. To compare harmonized and directed management;

4. To use the basic elements of the law-based behavior;

5. To define what is necessity and what is a condition during our work;

6. To define values and disvalues within the individual-mass ratio in order to stimulate the hardworking individual.

\section{Research Questions, Hypotheses, and Methodology}

Looking for valuable research results to recommend to those interested in this field, he/she thought that 
these would be the most appropriate research questions:

1. What is the meaning of the harmonized school management?

2. How many basic elements of this management should we consider to analyze?

3. What aspects of law-based behavior should be taken into account?

4. How many strong points do the philosophy of cooperation has compared with the directed management?

5. What are the positive indicators during the implementation of law-based behavior of school management?

6. What are the possible recommendations arising from this research to the homologous institutions?

This is the full hypothesis formulated for this research: The usage of law-based and culture-based behavior, during September-October, 2014 at BabëDudë (Karbunara) High School in Berat by the school principal with the teaching staff, has harmonized social relationships between staff individuals at school.

\section{Issues Covered}

\section{Analysis of the Situation at the Beginning of the Duty}

None of 40 high school teachers did not dare to run Karbunara High School. Four candidates were invited by the director of RED Berat to run this school, but they refused. One of the most applaused principal of the city ran this school in January, and then she resigned. Her (principal's) resignation shocked everyone. There was the fear that the job could not be done, and the belief and the optimism was down. Being in such a dilemma, finally, the decision to enter the game was taken.

Public opinion and family were against this decision. Even friends told that the job could not be done. The attitudes towards certain people and events are affected by our pleasant and unpleasant experiences. The school was devastated and it had made many steps back. Staff is divided, and each day you face a conflict of a magnitude that would disturb you. With regular procedure, the author came out the winner. Having a calm temperament, many people expressed their disbelief as this job could not be performed as a principle. The city called for a firm and arrogant principle. There could not be considered such a thing. Below, there are listed some of the school problems which firstly needed to be faced:

1. This high school with 925 students was led by the directive philosophy, orders, arrogance, and prepotency. Every day teaching staff meetings were held accompanied with an unpleasant atmosphere of insults and shouts from the beginning to the end of it.

2. The teaching staff was divided into many groups: some were her caressings, some her servilers, and some her (principal's) opponents who were unappreciated for what they were doing. This disunity was also conveyed to our students who bore the same frustration as their teachers. Frustration leads to stimulation of negative impulses to the degree of aggressiveness (Dollard, Doob, Miller, Mower, \& Sers, 1939). They were frequently used to attack each other (groups). In this atmosphere of high frustration, students broke all the rules. One of them said to the teacher "You get out of the classroom!"

3. More than 30 students of 12 classes stood at the entrance of the school during lesson time, the teachers did not dare to take attendance, and school exclusion was never heard. These students would not respect a single rule of the school. They entered different classrooms whenever they wanted. They walked through the halls of the school opening classroom doors and harassing teachers. These students smoke cigarettes in the school yard and bathrooms. None of them had books and other teaching tools. 
4. Teachers used students the way they wanted. Some used them for personal reasons and some gave them permission to get out of the classroom because they simply could not teach comfortably with these students in the classroom.

5. The whole internal atmosphere of the institution was characterized by unethical communication and unworthy vocabulary. Once the bell rang, students would get out in the hallway roaring, shouting, and whistling while some others were slamming the doors of classrooms, damaged as they were. They were a quite clear indication of very poor discipline of the educational institution, which was considered the most elite of this town. Aggressiveness is a concept with many dimensions, which is influenced by many factors.

6. It was a school in which its materials were not taken care of. The gym was now a warehouse and students were not having physical education. The basketball court was destroyed and the speakers were covered in dust. Chemistry laboratory was a ruin covered in dust. None knew where the physics tools and materials were. Teachers stood behind this taking no responsibility. All the clocks of the school did not function.

7. In terms of content, we found teachers who were not involved in actual, normal, and methodogical teaching. There were cases in which they were not good at interpreting scientific facts. Some students were punished in terms of assessment for personal interests and others were over stimulated for the same reason. Some of them complained about the assessments conducted by teachers as these tests had been prepared by teachers who violated principles and scientific and methodological norms. There were also teachers who would say, "You will see what the new principle will do!" Actually, they should have said, "You have to respect the law and school regulations."

8. In this state of atmosphere, they were waiting for the hero, the school principle, who even with a magic wand could not arrange and patch up everything within a year. Which were the first steps? It was needed to be familiar with the situation around, because some of the staff was unreliable. In order to get to know the others, it was the necessity to become as one with the crowd.

\section{From Directive to Collaborative Philosophy}

In terms of a democratic system with elements of free market and political pluralism, the management of orders and commands does not function without becoming a model when performing the duty. Modeling requires having the vision and conviction about what we want to do. Which was the method to conduct harmonization? That must be started form the headmaster. The staff wanted to see a principle different from the previous ones. He/she was to be of such quality, wise, calm, knowledgeable, kind, and dedicated, who spoke little but worked hard, forming a solid group. A manager who aims at performing his/her duty is someone who does his/her job. The social manager tries to form a solid group (Halpin, 1966). However, teachers were not familiar with this kind of principal and it was difficult for them to adapt to the new situation and model. So, the principal was to understand and be patient even when some of them did not take the turn in the positive sense at the right time. Everything was to be asked wisely respecting the law.

The moment that the introduction as a new headmaster was taking place, they learned that this manager was different. Speaking with a low tone voice and words but with strong content created an atmosphere of serenity among the staff. Many of them did not believe in this kind of communication. Some said that for this position there were needed more skills, others stated it was naivety and vulnerability. During the introduction or speech the author said that "Anyone could be there in my place but none of you dared" was said to be intelligent but also provocative. One of the things the staff liked at the beginning was the invitation made to all 
the teachers of this school with the following words: After the 6th class, all the staff is invited to the cocktail organized by me for being promoted as your new principal. Ironically, the author told them that if they would not come the author would cut their salary off for that day. None of them missed it. This fact impressed everyone. They said that they had not come together for a long time.

The manager of time should speak less and should lead by being a model so that he/she does not get tired. $\mathrm{He} / \mathrm{she}$ should be the first to come at work in the morning and the last to leave in the evening. This type of manager does not shout at the personnel ordering them to wear the uniform, instead he/she wears it himself first. One of the colleagues named E. B., when he saw the principal on wearing a uniform on the third day said, "Now, the author is obliged to wear the uniform, the principal wore it." This teacher had never worn a uniform because principals did not wear it. As all the factors and actors were against a good management of the most difficult school of the District of Berat, public opinion was right to think that the new principal could not his job. It was important to greet and smile to everyone, even though some of them did not deserve it. That was some kind of attitude that should be followed. This was to be done equally and in full harmony. It was the moment to be conscious that the school was in the responsibility of the headmaster as there was none to be relied upon. There was no air of reliability among the heads, teachers, and students. The principal had to follow all the movements of the students so he could understand them.

Someone criticized this kind of behavior saying that such action undermines the authority of the principal towards students and teachers. Moving inside the crowd means learning bad behaviours of students and teachers. This was provided by the movements of the principal. The principal did not intervene to solve them, but recorded the cases and asked head teachers and teachers to deal with them. The principal gave a piece of advice to teachers about these case that when you ask students to respect the rules, do not tell them this is principal's order, but tell them this is what the law or the rules say. Do not raise the cult of principal at school, because in democracy it is unhealthy, but raise the cult of law because this is how the mistake is corrected.

The principal became a partner and a collaborator of hardworking teachers taking into consideration every suggestion of them as an individual or as a group. The manager, in this case the principal should foster members to objector doubt about any decision taken. He/she should be impartial in discussions not to express his preferences in the beginning, but to collect information separately from any person and then in groups, so that they cannot influence each other (Janis, 1982). How were they given space to help? He said to this subgroup of teachers who actually were not a small number that they did not need to be a principal, but it was me who needed them. Imagine how any person will feel and behave if he/she is appreciated this way. They became more committed and more respectful to the new principal. Looking them in the eyes, humorously, the principal asked this subgroup that what was that weak point of the institution which was moving in the right direction so far. This was asked sincerely and with maximum accuracy. He also asked them how this problem could be solved. This type of engagement was a model of team work.

Methods to solve these problems were found by collecting opinions and suggestions from people who wanted to help and from people who knew the weak points of the school. This was achieved without plans, programs or sensational meetings. He asked for the support of passionate and hardworking teachers to come up with the best ways to solve the problems of the educational institution. They were also asked which point of the principal was the weakest. In reply to his question, they said that the disciplinary measure would be perfect for those who do not respect the regulation. He said, "What if we patiently continue to convince you that this is your duty and you have to do it properly?" They said it was the best method, but there were some 
teachers who did not understand, or they wanted to practically damage the reputation of the new headmaster at work.

One day, they will believe that the only way is that of respecting law, otherwise they will work alone. Lucky you! You are so patient, but please do not waste your time. It is not worth it! We will keep to the principle that everything is to be handled friendly, because we are friends in the first place. We are here to make more friends and fewer enemies. The rise and function of the group of the wise people as experts of the principal's office was a very important step in formulating policies and solving the hardest problems. This teaching staff that was not used to respecting the law had many difficulties at the beginning. Anything asked to them was perceived with suspicion. They thought it would not be fully applied. We will analyze the simplest aspect of formal discipline, the uniform of the personnel. Some of the teaching staff was to skeptic about it. They thought it was impossible for them to wear a uniform. They argued not to wear it. In a few words, they refused it.

The chairperson of the Union proposed another model, but they all changed their mind. They wore the uniform. Taking disciplinary measures was not considered the solution, because if they were taken, the situation would be worse and most of the teachers would refuse to wear it. The chairperson of School Union was finally convinced to wear the uniform when one of his close friends insulted him by telling him a joke. When elements such as law-based behavior, tolerance, and friendly intervention came together, one of the most valued teachers of the school started to wear his uniform. This is a simple indicator but very significant as the most prestigious school of the district had made many steps backward.

\section{Case Study}

The school vice principle insults a teacher at the school hall in the presence of crowds of students. The teacher complains at the principal's office. She was touched, furious, and overreacted. The principal suggested her to write a letter of complaint to the commission of ethics and behaviour of the school. The teacher said that this commission could not be trusted as it was influenced by the vice principal. Even though it was true, she wrote her complaint letter. Commission of ethics and behaviour acted correctly asking both parties to bring themselves in. The vice principal does not consider it. She underestimated it with arrogance. She did not even want that both parties meet at the principal's office. She insisted in not being present when the commission called her and she said that she would again insult her colleague. A disciplinary measure was taken by the Disciplinary Commission.

This case is mentioned in order to highlight the level of cultural and law-based behavior of social relationships in the main high school of Berat which was considered the academy of generations. Three years earlier, this school was awarded the third prize in Matura State exams. It should be emphasized that the vice principal of the school which for six months had the role of the principal, did not talk to $2 / 3$ of the personnel. Principal's cult had produced an institutional conflict in communication which could be solved by replacing this kind of vice principal who had helped in producing it. It was very difficult for the principal to carry out the replacement as it was to be based on law. We are not allowed to dismiss someone without offense. Certain steps were to be taken, so that she could be dismissed. All of these were taken within a short period of time and everyone got what he/she deserved.

A vote of confidence preceded her dismissal. The principal got 38 votes out of 40 . The first vice principal got 32 out of 40 while the vice principal that was to be dismissed got 16 out of 40 . She could have gotten less 
than that if the voting could have been more carefully handled. After the announcement of the results by the commission, the principal revealed her dismissal and asked her to express herself. She was angry and did not accept to speak, but once the meeting was over she went to the principal's office to express that what had happened was just a farce. She did not want the motivation be read in front of the Council of Teachers, because she was sure it would be motivated as a consequence of what had happened. Before dismissing her, we asked for her resignation three times, because it was a tricky person who could not be trusted. She was too confident in her arrogance and she thought that we could not work without her. A euphoric, arrogant, and haughty behavior with a non law-based logic does not function in contemporary management of educational institutions.

How did the community react to her dismissal? She refused to resign because she said she had no reason to do it. In their first friendly conversation, the principal said to her, "I have never heard a person praising you or your job. None has ever advised me to keep on working with you." When the news spread, many citizens and people who had worked in educational institutions expressed their gratitude for the decision taken. The personnel and students, who knew her appeased, she was simply doing her job as a teacher now, but she was always unpredictable in what she does.

\section{Achievements of Law-Based Communication Behavior}

Speaking of law, people stop and watch if it is being respected. Every reaction which gives satisfaction in a certain situation is associated with the same situation even when the situation is repeated. The reaction will happen again (Thorndik, 1932). This was what the teachers were waiting impatiently. Even the previous teachers had spoken about the law and the rules, but they had broken them themselves first. These were principals with high reputation in their profession. But, these are not small values when you commit yourself to your duty. This institution had never seen so far a principal wearing his uniform from 7:30 a.m. to 13:30 p.m. everyday.

He never had a coffee at the bars in front of the school even when friends and teachers persistently invited him. He hated this habit of his colleagues gossipping at the bar for hours during breaks. If he needed anything, he asked the secretary. He did not leave his office for a minute. This was what he asked to his close staff, vice principals and secretary. He said, "We have to start from ourselves. If we can not do it, then we should consider replacement" during the first meeting. We do not lack anything to perform our task. The community expects a lot from us. If we disappoint them, we should resign and someone else may replace us. The first disciplinary measures will start from us, so we are morally right to ask the others respect the rules and the law.

The staff needs to understand that the principal loves and treats them all equally. This is also more effective when individuals have emphasized ego. They are greeted equally and they analyze every detail of this greeting. Due to their sistematic and high conflict with each other and with the previous principals, he does not respect others, because they think it is a decline of their authority. The criterion of equality and harmony was kept balanced with responsibility and appreciation. Everything was carefully handled. Teachers' performance card played a very positive role in the assessment of each participant. It was detailed with basic indicators formal discipline. Indicaters included: punctuallity, daily preparation, student's behaviour, uniform, communication, commitment to duty, and reporting on time.

The principal had also to be careful when having coffee: There were many groups of teachers and if you had coffee with one group the other might have been provoked. So, the principal chose not to have coffee with none of the groups during working hours. If teachers had to express themselves, to propose or to complain they could 
do it by writing it and not orally. Classes and courses were given by lot. The staff structure was not appointed my the principal. They were elected by secret proposal and vote. The Internal School Regulation was approved with full transparency from the Council of Teachers asking them for any further suggestion.

\section{Harmonization Indicators of the Personnel}

After three female principals, a male one was expected from in and out of school. The author does not understand why they were tired of their conflictual management as women are known for their tenderness. They say that one of the reasons is the management atmosphere and the climate which was not law-based but abusive. The other reason is the fact that $80 \%$ of the teaching staff is women and it is difficult for female principals, because they are not preferred by women as they are known to be jealous of each other. A new male principal with gentle temperament and experience with a law-based behavior was warmly welcomed. The teaching staff was to respect the principal because of his low voice, well-thought-out actions, smart jokes, and ethical praise. They said they needed such a manager as the school had only been managed by arrogance. One teacher from the staff was confused and she could merely walk. She had experienced a nightmare during the previous school management. Another colleague notices her behavior and one day he comes at the office saying, "You have healed K. H." The truth is that the author had asked her about her health condition but nobody knew about this.

Table 1

The Representation of the Changing of Some Features During the Period February 2014-October 2014

\begin{tabular}{lllll}
\hline No. & Indicators & February 2014 & October 2014 & Difference \\
\hline 1 & School attendance & $34 \%$ absence & $6 \%$ absence & $28 \%$ absence \\
2 & Without books & $26 \%$ & $2 \%$ & $24 \%$ \\
3 & Smokers & 38 students & two students & 36 students \\
4 & Students who spoil the lesson & 32 students & four students & 28 students \\
5 & Communication & weak & good & \\
6 & Law enforcement & $60 \%$ & $95 \%$ & $35 \%$ \\
7 & Festivity & high & low & \\
8 & Stress level & high & low & medium \\
9 & Respect level & low & high & \\
10 & Transparency & low & low & \\
11 & Gossips level & high & high & \\
12 & Focusing on duty & low & real & \\
13 & Objectivity & not real & easy & \\
14 & Adaption & difficult & low & hormal \\
15 & Aggressively & high & low & \\
16 & Will & low & high & high \\
17 & Hypocrisy & low & high & \\
18 & Reliability & low & low & \\
19 & Authority & Satisfaction & & \\
\hline
\end{tabular}

Another female teacher was keen on gossips. She liked talking about others. One could understand she could not sleep at night. Advicing her to stop gossiping and to start worrying and committing to her job this way she would avoid stress and she would become healthier. In many cases, in which the problem is not solved, stress is the result (Rice, 1987). She followed that kind of advice and soon her complexion changed. A few days later the teacher expressed gratefulness for the psychological advice and wherever she went, she praised the 
school principal. Bringing such a climate in the school in the very first month helped the author achieve the goals later. In the institution, a relation of law-based and friendly behavior was now installed. The following table is about some indicators of school harmony, which was applied in this school through the philosophy of harmonized school management indicated by the head of the institution (see Table 1).

\section{Conclusions and Recommendations}

1. The directive philosophy of managing educational institutions, which essentially results in personal benefit by school principles, is a total failure recently. The philosophy of collaboration harmonizes social relations among the teaching staff and optimizes the atmosphere of the educational institution;

2. Law-based behavior communication motivates and enforces the teaching staff to do their job according to the latest development in teaching. The individual becomes aware of the law enforcement by reinforcing it step by step. A tender communication is more persuasive and strongly respected by individuals who are hard-working;

3. A principle that runs a school by becoming a model to follow does not need to give orders or command. He leads by his example. People are not satisfied with words but with deeds;

4. Delegation of competence to the teaching staff according to the law and regulations encourages and enforces the staff to perform their duty. Teamwork creates better results when it is appreciated by the head of the institution. In front of the group-stimulate, outside of the group-criticize, this principle does not produce conflicts in educational institutions.

5. The head of the institution should not become a part of any of these groups because the conflict continues to deepen. His attitude should be clear and firm. He should not be part of the gossips. He should quench the conflicts;

6. The principle of secret voting and lot in electing the structures of educational institution is a necessity that satisfies the teaching staff. Furthermore, these institutions function at the highest level of law-based behavior communication;

7. The teaching staff should be convinced that the principle loves them all equally. This is the most delicate moment because of the extent to which it will be respected.

\section{References}

Dollard, J., Doob, L., Miller, N. E., Mower, O. H., \& Sers, R. R. (1939). Frustration and aggression. New Haven: Yale University Press.

Deci, E. L. (1975). Intrinsic motivation. New York, N.Y.: Plenum.

Halpin, A. W. (1966). Theory and research in administration. New York, N.Y.: Macmillan.

Janis, I. L. (1982). Victims of groupthink: A psychological study of foreign-policy decisions and fiascos. Boston: Houghton Mifflin.

Johnson, R. N. (1972). Aggression in man and animals. Philadelphia: Saunders.

Petty, R. E., \& Cacioppo, J. T. (1985). The elaboration likelihood model of persuasion. In L. Berkowitz (Eds.), Advances in experimental social psychology (Vol. 19). New York: Academic Press.

Rice, P. L. (1987). Stress and health, principles and practice for coping and wellness. Monterrey, C.A.: Brooks/Cole.

Thorndike, E. L. (1932). The fundamentals of learning. New York: Teachers College Press.

Zajonc, R. B. (1965). Social facilitation. American Association for the Advancement of Science, 149, 269-274. 